\title{
FROM THE GENERAL DOCUMENTATION OF HADRIAN'S VILLA TO DESIGN ANALYSIS OF COMPLEX CUPOLAS: A PROCEDURAL APPROACH
}

\author{
L. Cipriani ${ }^{1}$, J. García-León ${ }^{2}$, F. Fantini ${ }^{1, *}$ \\ ${ }^{1}$ Department of Architecture, Alma Mater Studiorum - University of Bologna - (luca.cipriani, filippo.fantini2)@unibo.it \\ ${ }^{2}$ Dpto. Arquitectura y Tecnología de la Edificación, Universidad Politécnica de Cartagena - josefina.leon@upct.es
}

\author{
Commission II, WG II/8
}

KEY WORDS: Hadrian's Villa, Topography, Terrestrial Laser Scanner, Photogrammetry, Reverse Modelling, Procedural Modelling

\begin{abstract}
:
The paper illustrates the progress of Hadrian's Villa digital documentation with special emphasis on a series of modelling issues emerged while studying vaults and cupolas of the site. Together with the more general problem of giving scientific coherence to both active and passive sensor outputs - systematically gathered from 2013 - a methodological problem concerning data interpretation of complex opus caementicium vaults have become dramatically important for the interdisciplinary research team. A methodology for improving the understanding the original shapes of Hadrianic cupolas was designed to provide scholars and professionals operating at the Villa with reliable and easy to use outputs, for interpretation, restoration, maintenance practice. Sensors integration played a fundamental role since allowed researchers a global understanding of intrados and extrados surfaces using reverse modelling applications. Features and 2D primitives extracted from high-resolution models were analysed in order to create flexible procedural models of reconstruction hypothesis/completion of cupolas. Due to the very nature of these shapes (apparently irregular), but with a solid geometric conception, we applied the last achievements of Catmull-Clark bicubic surfaces in combination with Visual Programming Language (VPL).
\end{abstract}

\section{INTRODUCTION}

Among the studies and research on Hadrian's architecture over the last fifteen years, significant progress has been made on the high reliability of surveying systems based on laser scanner technology (active sensors) and, more recently, on new photogrammetric procedures based on computer vision advances (Gonzalez-Aguilera, 2018). The products of these methods have allowed a more effective documentation, of elevations and roofing that are still in good conditions and characterize the Villa (Figure 1 and 2). In addition to the documentation of the large domes in opus camenticium (Lancaster, 2005), digital surveys have also allowed significant insights and a careful review of another particularly interesting theme, the documentation and analysis of the architectural decoration with a mixtilinear patterns, another distinctive feature of Hadrian's architectural production (Adembri et al., 2016).

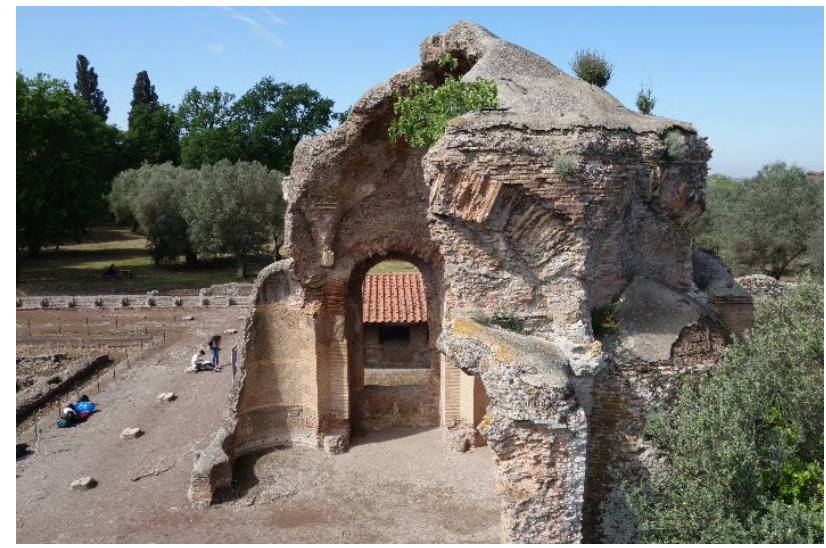

Figure 1. Access Vestibule to the Golden Court: this central plan building is adjacent to the portico that gives the name to the complex.

\subsection{Hadrian's Villa: general layout}

More than a villa, Hadrian's mansion is like a real city, spread over an area of about 120 Ha during antiquity (Pompei doesn't go far beyond 60 hectares); now it covers more or less $40 \mathrm{Ha}$. The Villa extends over a long tufa plateau surrounded by small valleys to the east and west containing two streams. The site slopes gently along a north-south axis, naturally ensuring drainage, as well as water supply. The grandiose complex is divided into different cores, differently characterized and with different alignments: representation areas, for conviviality and entertainment, baths, the Imperial Palace, the Summer Residence, and so on. A network of subterranean passageways seems to be constructed during the very first stage of the complex - tracked to a length of 4,8 km (Opper, 2008).

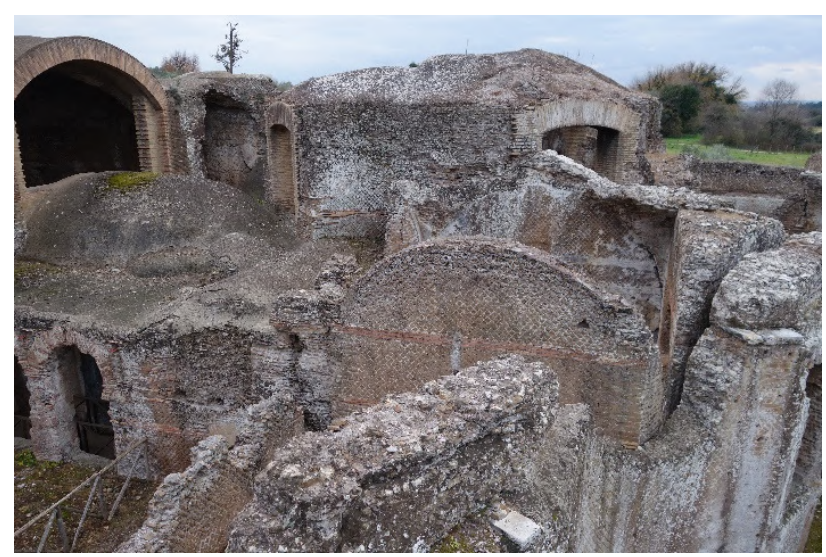

Figure 2. Picture showing the complex shape of Small Baths' roofing made of intersecting volumes.

\footnotetext{
* Corresponding author
} 
Even if not all the scholars converge on a common position, it is safe to say that the general development of the Villa started from a Republican nucleus located northeast of the general boundaries of the mansion. A second development was along the two expansion lines flanking the Colli di Santo Stefano. After a first hectic construction phase (118 A.D./121 A.D.) aimed at creating the Palace complex (used for official and political functions), Hadrian's personal domus (the Maritime Theatre), a vast portico (the Poecile) and a thermal bath (Heliocaminus Baths), a second and more "intellectual" building program began (125 A.D./128 A.D.). All the functions and typologies included in the first phase were replicated outwards along the two expansion lines. This tendency seems to underline the Emperor's intention of constant renewal, enrichment and enlargement of triclinia, thermal baths, and nymphaea. In this frame, made of about 900 rooms and corridors, domical structures have always been a crucial aspect of the Villa as well as a Hadrian's legacy. Recent studies on the Villa's comprehensive layout underlined the importance of the main domes and, more in general, central plans, as "knots" of a polycentric composition (Caliari, 2018).

\section{METHODOLOGY}

\subsection{Surveying issues}

Interpretation studies carried out on Roman vaults and cupolas are in general focused on intrados shapes, rather than on a more complete analysis including both intrados and extrados (Verdiani et al., 2011; Aliberti and Alonso-Rodríguez, 2018).

In this case, the need for completeness of digital models is a priority to determine clearly the less obvious aspects of the building construction, as well as reaching a general methodology for Roman cupolas investigation.

In the cases of Small Baths and Golden Court's Vestibule, after several surveying campaigns, we achieved complete mesh models with an edge average length ranging from 4 to $8 \mathrm{~mm}$. The decision to work with triangular meshes is due to the next phases of the proposed method that is aimed at exploiting the potentials of reverse modelling applications addressed to shape interpretation and mesh comparison (reality-based models and idealized models from geometric modelling applications).

Two different outputs were necessary to our purposes: the first one is a bidimensional representation composed by canonical drawings as plans, façades and sections, mostly used to quantify areas and volumes for maintenance and restoration works and to setup the construction site (Figure 3 and 4). The second aims to outline the basic geometric shapes, conceived by the architect during the design phase, and to exclude many "false clues", i.e. those alterations in shape introduced by anthropic causes (restoration works, reuse of construction materials) and natural causes (damages of runoff waters, freezing cycles). The relationship between these two outputs is very close, since the interventions planned must consider not only the specific conditions of the present situation, but also the idea underlying the initial architectural design. The latter is inevitably altered by the course of time and by the various functions to which the building has had to carry out.

\subsection{Design analysis of plan layouts (ichnographia)}

In ancient times, designing activities were not split - in positivistic terms - into architectural design, structural project, construction logistics, plant design, execution, finishes, etc. An abundant literature on this subject is present (Wilson Jones, 2000), but in this case, we are focusing on two concepts/terms affecting design analysis: ichnographia and orthographia.
Ichnographia was a technique, expression of proven geometric patterns, addressed to the definition of building layout (as, for example, the determination of the parts of the theatre using an easy to reproduce graphic algorithm in accord to Vitruvius). It was aimed at facilitating the solution of functional, distributive, structural and constructive problems. The second technique applied to designing was orthographia: starting from the plan, the elevation was determined through precise ratios, modules and geometric patterns.

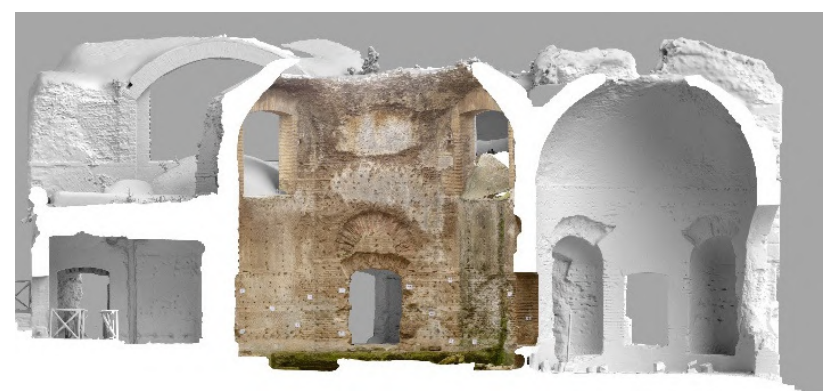

Figure 3. Section of Small Baths in compliance to restorers' requirements: orthographic views of a mesh model with texture applied on the area of main interest.

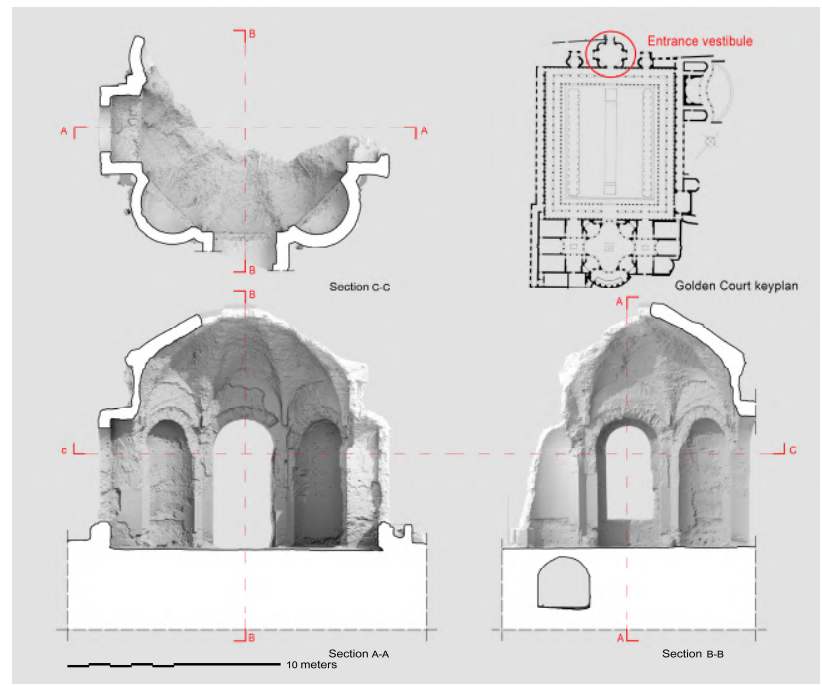

Figure 4. A comprehensive set of views of the Entrance Vestibule to the Golden Court: intrados was from TLS and extrados from photogrammetry.

Among technical texts on this topic (Heiberg,1914), only a few of them, are still preserved, but it is safe to say that architects operated with two protocols: first they applied geometric patterns for a general definition of layouts and facades. Once they produced several irrational quantities through compass, they had to make fit those irrational measures into finite quantities for two reasons. The first was for the achievement of simpler calculation of areas and volumes for the metric estimations, the second was the ancient habit of using grid-based designs in order to facilitate several practical issues of the construction process, namely due to standardized constructive elements as bricks. A complex shape like a Roman cupola in opus caementicium must be investigated inside its context, since the grid-based design was applied to all the parts of the building: plan, elevation, constructive elements. In the case of Small Baths at Hadrian's Villa, Rakob (1967) identified the presence of a modular grid of 5 pedes that he applied to the internal profile of the octagonal hall. 


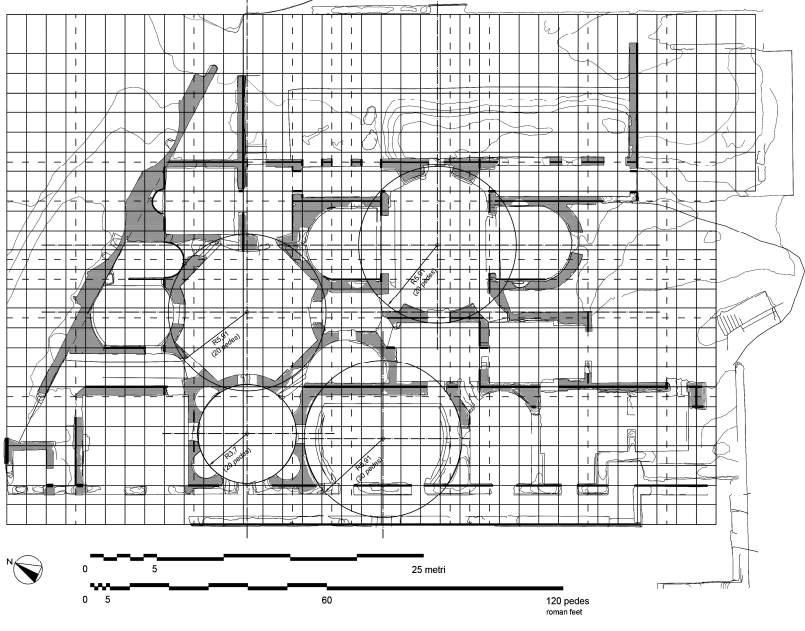

Figure 5. A hypothesis on the modular grid of Small Baths.

The German researcher found they used a square made of $7 \times 7$ moduli for the internal dimensioning of this hall, while the bending radius of the curved sides was of 15 pedes. In Figure 5 we applied the same modular structure to the whole building. The grid is used as a flexible tool: walls are alternatively aligned to the grid using their centres, interiors or exteriors surfaces depending on the situation. Focusing on design interpretation of Hadrianic architecture, a major issue is the understanding of geometric rules responsible for the continuous alternation of straight and curved lines: in particular the definition of centres and radii. This sort of graphic "algorithm" was the "core" of ichnographia. Due to the state of conservation of masonry, as well as the presence of restorations, it is necessary to introduce several cutting planes in order to intersect original ancient elements and analyse the best-fitting circumferences (Figure 6a), that may lead to inappropriate results if it's seen from the pure numerical point of view (Figure $6 \mathrm{~b}$ ). The main problem deals with the high dispersion around average values (Table 1), graphically expressed in Figure 6 (b and c).

\begin{tabular}{|c|c|c|}
\hline Side & Metres & Pedes \\
\hline North & 4,04 & 13,66 \\
\hline East & 4,27 & 14,44 \\
\hline South & 3,81 & 12,88 \\
\hline West & 4,35 & 14,71 \\
\hline Average & $\mathbf{4 , 1 2}$ & $\mathbf{1 3 , 9 2}$ \\
\hline
\end{tabular}

Table 1. Internal best-fitting circumferences extracted from Geomagic Design X.

It is difficult to reconcile the sum of the factors listed above with the tolerances typical of current surveying tools, as well as with all the engineering software that allow to extrapolate information from digital models. In the octagonal hall of the Small Baths the layout is evidently asymmetrical. The reason cannot be simplistically reduced to lack of accuracy in the construction due to the hectic, probably syncopated, progress of the construction. A geometric pattern was present, but in the final construction phase it must be altered due to the high experimental degree of these vaulted spaces. In order to find a possible solution other building at the Villa supply possible clues. However, a structural interpretation emerges from a correct consideration of MacDonald and Boyle (1980): they pointed out the mixtilinear octagon presents seven "holes" (Figure 6b), corresponding to as many doors or passages.
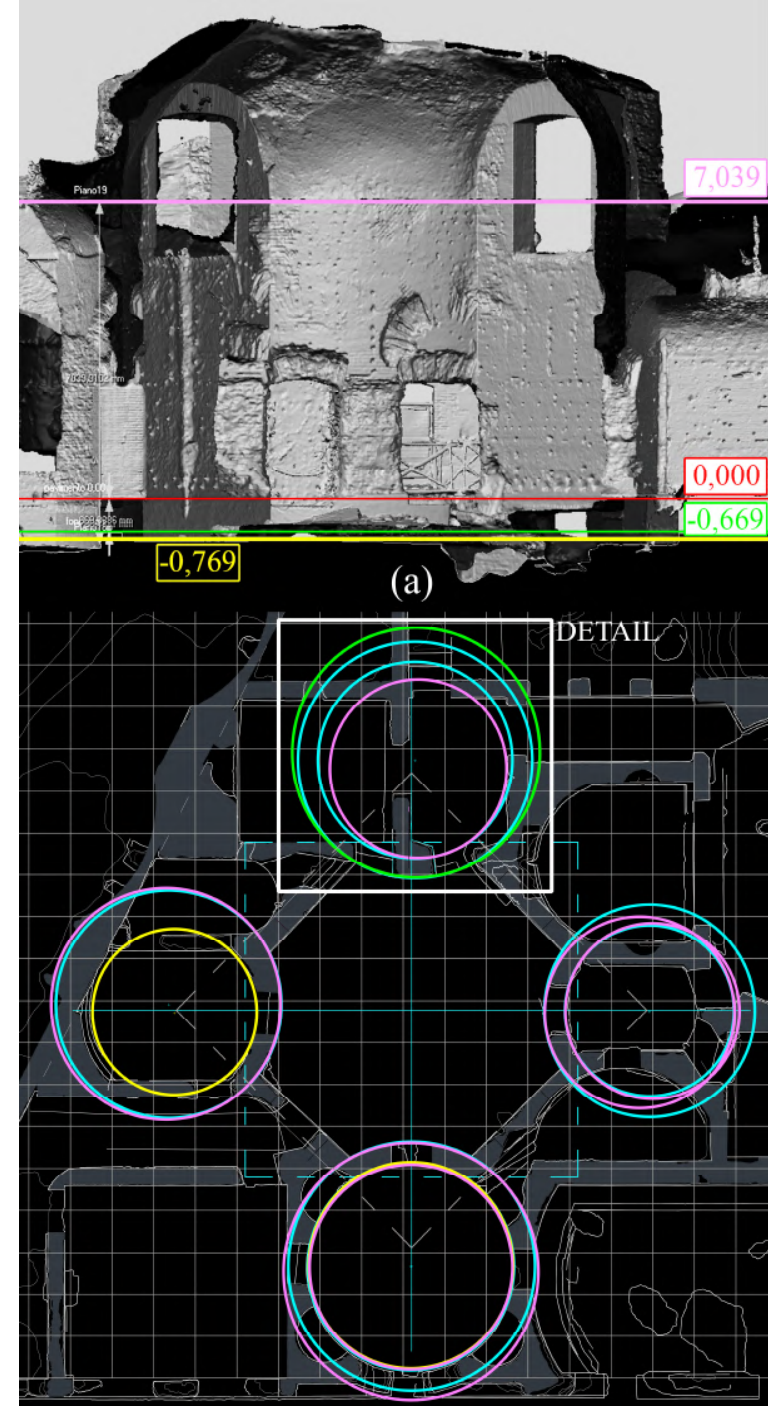

(b)

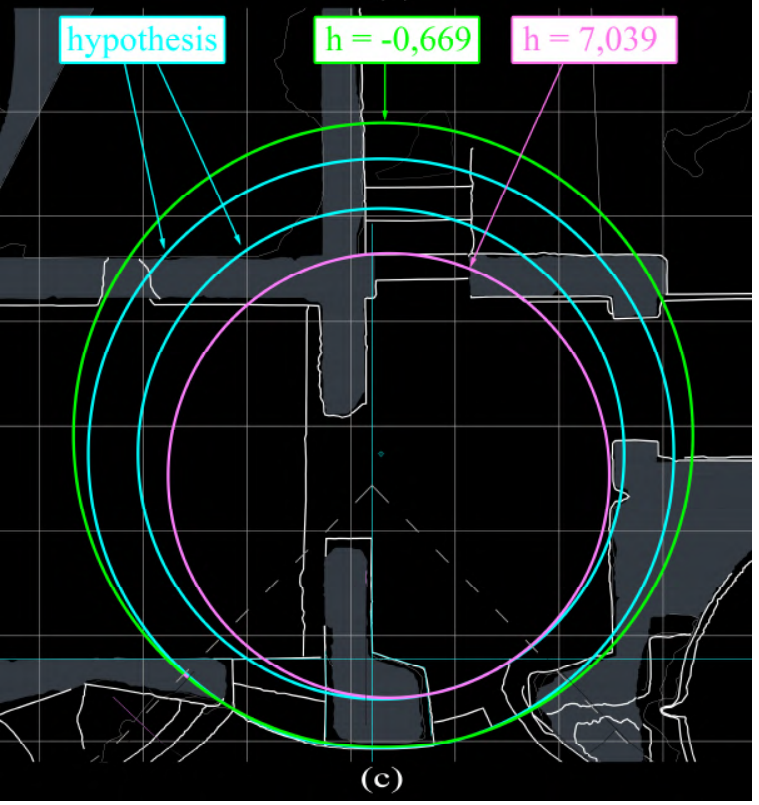

Figure 6. (a) Identification of section planes. (b) General plan of Small Baths with best-fitting circumferences extracted by Geomagic Design X. (c) Best-fitting circumferences and hypothesis. 
Only the edges are not touched by this daring series of "material subtractions" (masonry "pillars" thickness is equal to 2.5 pedes): the straight walls look like diaphragms, with variable thicknesses due to the presence of curvilinear bodies that seem to "erode" the very thin walls. One edge is weaker than all the others: the eastnorth-east one (Figure 6c). Here the straight wall is thickened (exactly 3 pedes), that is probably a precautionary measure taken by the architects. They avoided the risk of weakening one of the piers by interrupting the symmetry of the structure and strengthening (as much as possible) that side of the octagon. Similarly, even in the vestibule of the Golden Court, we can observe an equally daring design choice and a palliative that did not avoided the collapse of the southern portion of the dome. The vestibule is a thin independent volume, unlike the octagonal hall of the Small Baths (Figure 7 and 8).

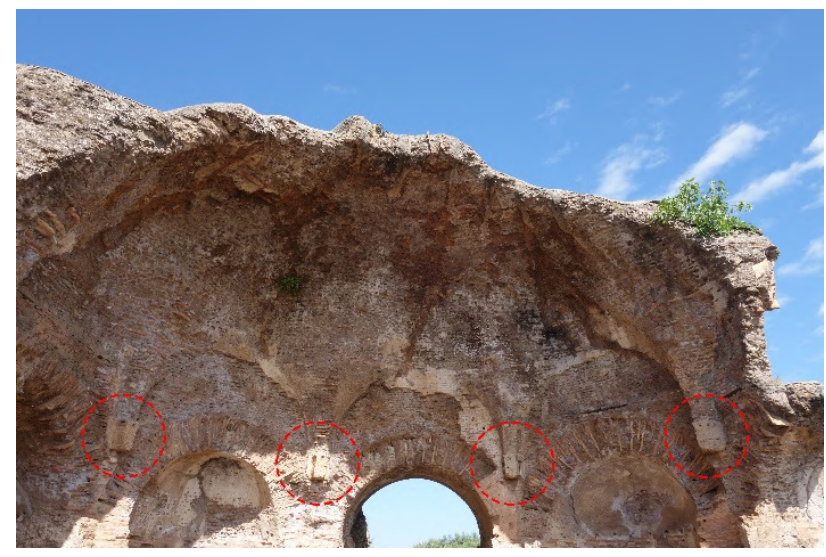

Figure 7. the Vestibule dome with pulvini highlighted.

The average thickness of walls is 2 pedes; brick pillars supporting the travertine pulvini are thicker and regularly arranged on six of the eight points in which the large dome transmits its weight (Figure 8a, detail 1). The exception is the side adjacent to the portico of the complex: here the brick pillars have a smaller resistant section than the other six. In this way the depth of the portico wall (where the vestibule is set up) results unaltered. In this case too, there is a slight thickening, not enough to prevent the collapse of the dome on this side (Figure 8a, detail 2). Moreover, this part is subject to instabilities due to the below cryptoporticus, that connects with the underground road (via tecta) to the East of the Villa. Differently from Small Baths, at the Golden Court the grid-based design is clearly underlined by the rhythm of brick columns. Centre to centre distances varies significantly (Table 2):

\begin{tabular}{|c|c|}
\hline Side & Average measure in pedes \\
\hline North & 5,51 \\
\hline West & 5.31 \\
\hline South & 5.47 \\
\hline East & 5.48 \\
\hline Average & $\mathbf{5 , 4 4}$ \\
\hline
\end{tabular}

Table 2. Centre to centre distances of Golden Court columns.

The comparative study of the Vestibule and the Octagonal Hall allowed identifying some elements in common with both central plan buildings. They share a modular grid, even if with different measures (approximately 5.5 and 5 pedes), both are central plan buildings, and their designs are the product of geometric constructions based upon circles and inscribed squares shaping linear and bended sides.

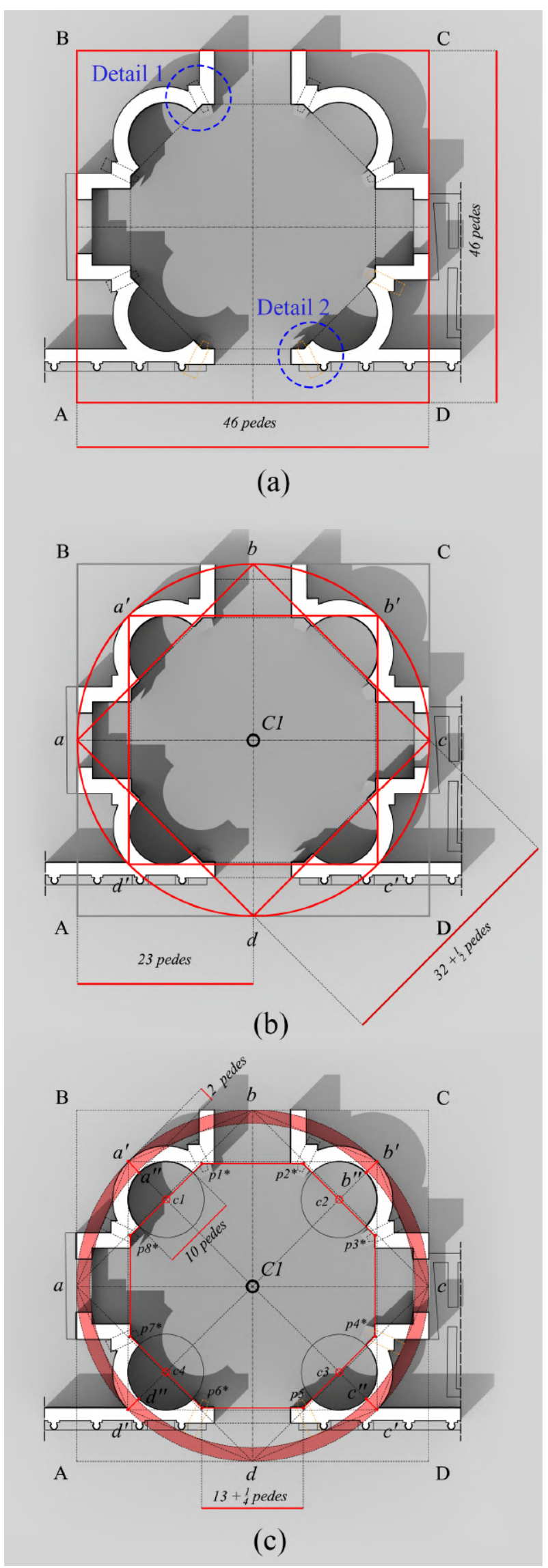

Figure 8. Entrance Vestibule to the Golden Court: (a) general dimensioning; (b) definition of the layout; (c) walls' dimensioning hypothesis. 
But a difference is evident: the volume of the vestibule is regular and isolated from the rest of the Court while Small Baths' Hall is in the very middle of overlapping, interpenetrating volumes (Figure 1 and 2). Since the Vestibule is more regularly built it supplies several hints for a better understanding of Small Baths' mixtilinear octagon. The crucial aspect is to understand, from the ancient point of view, the relationship between design and structure: Giuliani (1975) hypothesized - without deepening the issue in rigorous terms of ichnographia and orthographia - that the section of the load-bearing brick pillars of the Vestibule were the product of a "geometric dimensioning". Giuliani also notes that the pillars are lacking in coaxiality with respect to the radii of the octagon. Form the reality-based model we can observe:

- The circle with a 46 pedes diameter inscribes a square of 32.5 pedes (Figure $8 \mathrm{a}$ ).

- An octagon (a, a', b, b', c, c', d, d') is constructed with a $45^{\circ}$ rotation of that square (Figure $8 \mathrm{~b}$ ).

- The offset amount between circumscribed and inscribed circles to this octagon defines geometrically wall thickness with a difference of 1 palmus $(7.39 \mathrm{~cm})$, so the thickness of the walls (with the exception of the pillars) is resized "ad abundantiam" to 2 pedes (the problem of fitting irrational quantities with whole numbers or, at the very least, with rational numbers).

With this design analysis, not lacking in gaps and aporias, but coherent with the elementary geometric constructions used to define layouts, we obtain an internal octagonal profile of side equal to 3.92 metres, or 13.25 pedes. The niche openings measure 10 pedes. Returning to Small Baths' mixtilinear octagon, in the light of the foregoing, it is possible to note that a planimetric grid of 5 by 5 pedes verifies many of the alignments present in the Small Baths (Figure 9a). The circle - inscribed inside the square $\mathrm{ABCD}$ of 40 pedes sides - seems to regulate the size of the octagonal hall (including the wall thickness), but it is translated by a pes horizontally and vertically, with respect to the planimetric grid. This is probably the outcome of the adjustment previously explained concerning the weakening of east-northeast corner of the structure (Figure 6c). If we do not consider this eccentricity and we look more broadly at the building plan, including the nearby volumes of the other rooms, we can see an interesting series of coincidences:

- Applying a $45^{\circ}$ rotation to the square of 40 pedes, we obtain the common construction for the octagon drawing (Figure $9 b)$.

- The vertices of this square - aligned to the general grid along the diagonals - are close to the centres of the circumferences that determine the curved sides of the internal profile of the octagonal space.

- The external rectilinear sides of the octagon are tangent to the variable radius circumferences that are positioned around the room.

The room is designed on a 40 pedes square, the interior is also based on a rotated grid of 7 moduli of 5 pedes, in accordance with Rakob (1967), and the thickness of the walls is equal to 2.5 pedes (half a module, Figure $9 b$ ).

\subsection{Design analysis of elevations (orthographia)}

The comparison of both buildings, moving towards orthographia, leads to further general reading keys on the role of geometric patterns. As general statement the grid-based design was not just limited to the plan, but included sections, elevations, and façade design, as it clearly emerges from the analysis of the southern wall of the Golden Court whose plan layout is based on an average module of 5,44 pedes as formerly shown in table 2 (Figure 10).

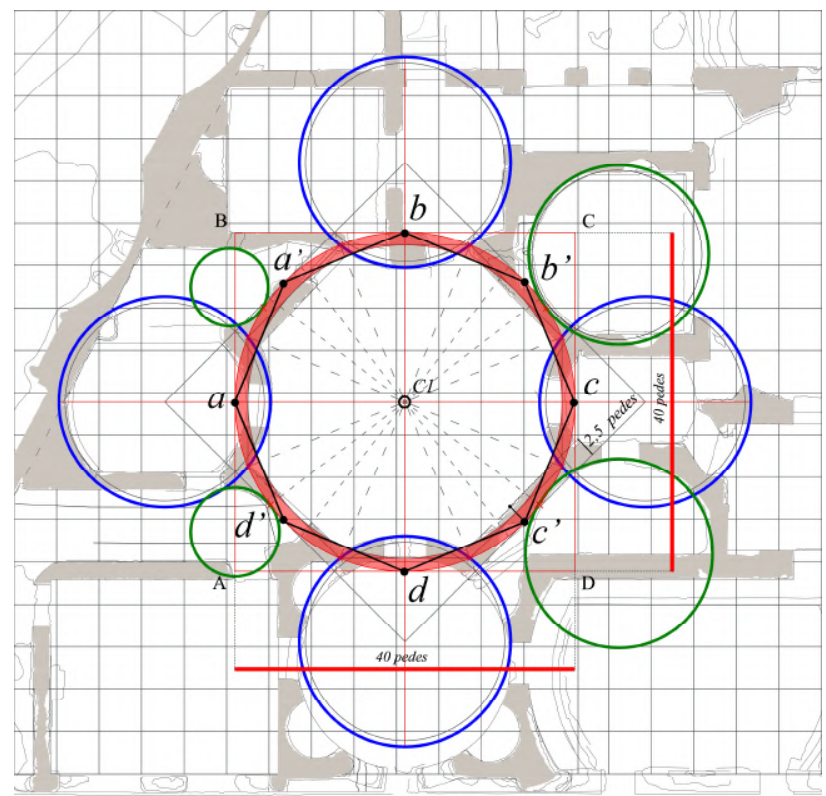

(a)

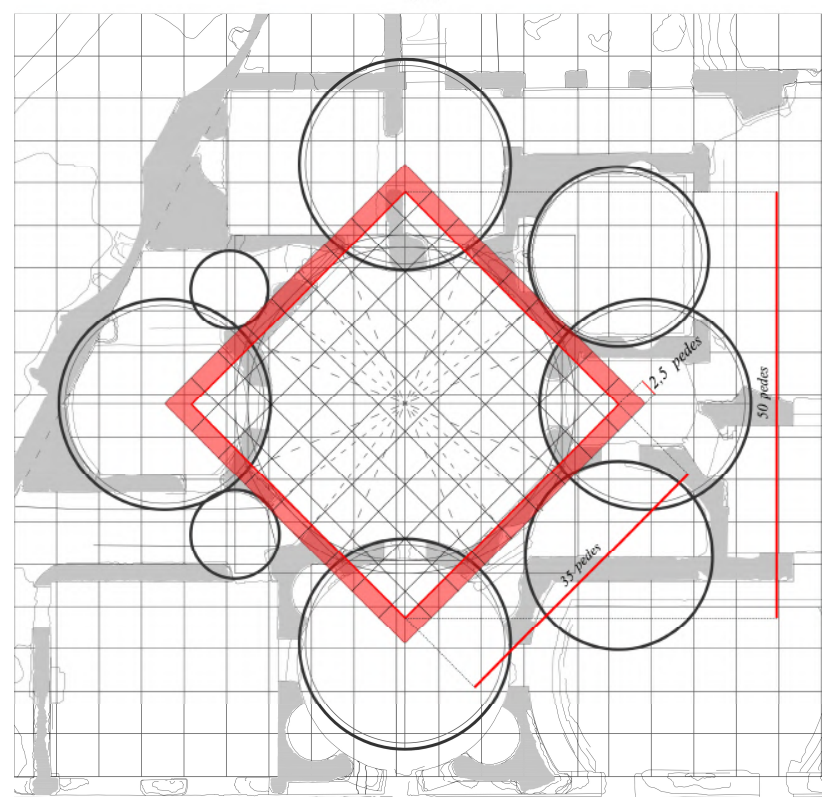

(b)

Figure 9. Octagonal Hall: (a) similar designing features emerge from the comparison with the Vestibule; (b) the 5 pedes grid is rotated and determines thickness of walls (half module).

The geometric analysis of the south wall is a prime example of how the grid was applied by ancient architects in order to give consistency to structures, as well as to facade decoration. For the interpretation of Small Baths' octagonal hall, it is safe to say that the architect applied simple ratios to the dimensioning of interior volume (Figure 11).

Morphological information extracted by Geomagic Design $\mathrm{X}$ gave evidence: a diameter of 10.44 metres, corresponding to 35.31 pedes, is the result of a vertical section passing through the centreline of the curved sides of the hall, interpolated with bestfitting circles passing through the intrados preserved surface. 


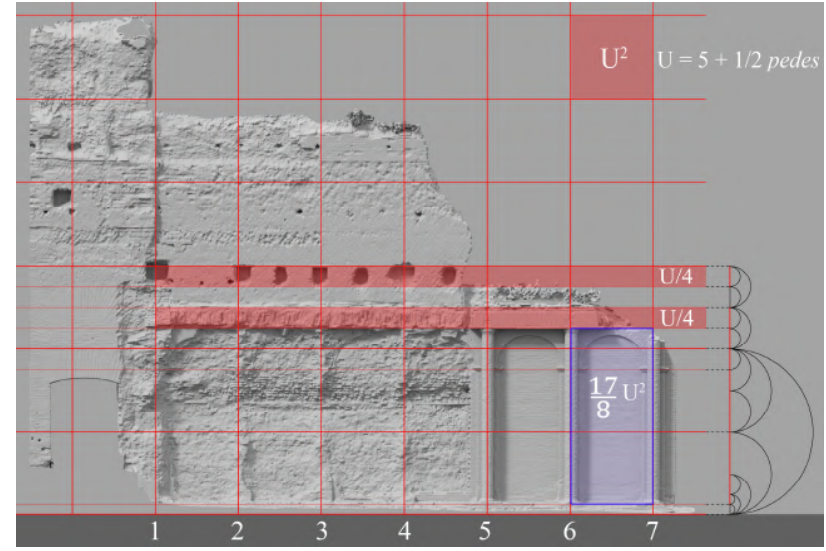

Figure 10. Façade design of the Golden Court.

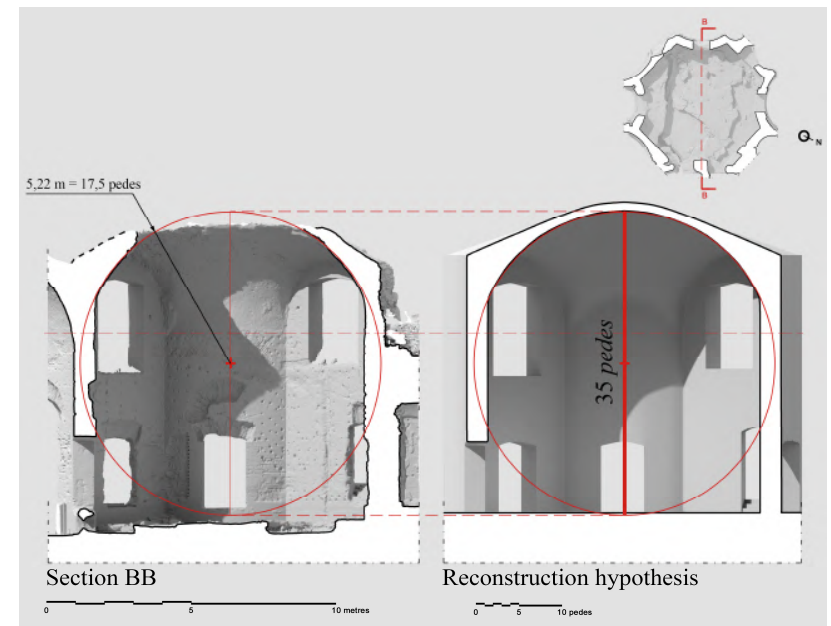

Figure 11. Best-fitting circle extracted from the intrados.
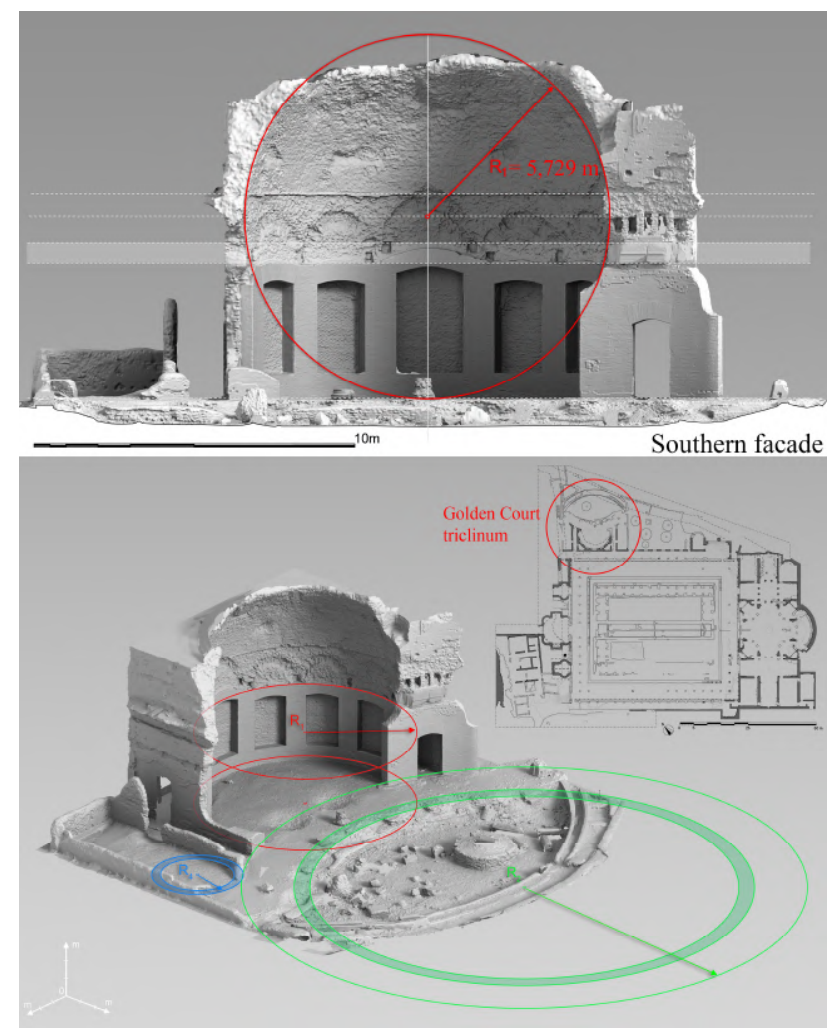

Figure 12. Triclinium of the Golden Court.
A 1:1 ratio was adopted by the architects for linking plan layout and elevation ( 35 pedes). In the case of the Vestibule the situation is less clear since the classic 1:1 ratio - also present in another cupola at the Golden Court - seems to be missing.

The triclinium in the north-east corner of the court has a clear relation that links plan and façade (Figure 12): the radius $R_{1}$ of the layout central space is equal to $5.729 \mathrm{~m}$, consistent with the module (U) formed by 5.48 pedes present on that side of the portico (Table 2):

$$
\mathrm{R}_{1}=3,5 \mathrm{U} \text {. }
$$

The hemispherical dome covering this space has a radius equal to $\mathrm{R}_{1}$. In Figure 13 a possible interpretation of the relation ichnographia-orthographia present in the Vestibule is shown: the dome is smaller than the one of the triclinium since the average radius of the sphere is equal to 3 modules of 5.5 pedes (Table 3).

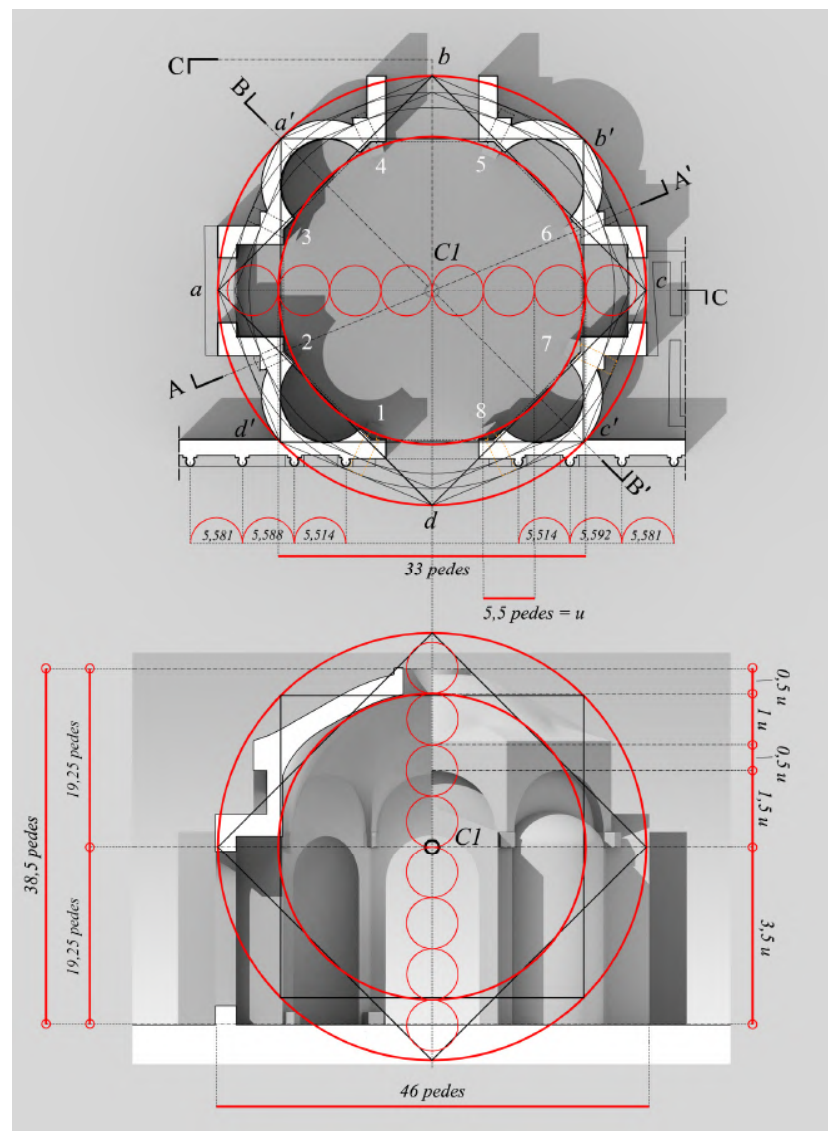

Figure 13. Even if characterized by different proportions, the Vestibule design results consistent with the impost line of the nearby Triclinium and the grid-based design of the portico.

\begin{tabular}{|c|c|c|}
\hline Pulvini & Metres & $\begin{array}{c}\text { Module U }=5.5 \\
\text { pedes }\end{array}$ \\
\hline $1-5$ & 4.9799 & $3.063 \mathrm{U}$ \\
\hline $2-6$ & 5.0588 & $3.111 \mathrm{U}$ \\
\hline $3-7^{*}$ & 6.443 & $3.962 \mathrm{U}$ \\
\hline $4-8$ & 4.943 & $3.040 \mathrm{U}$ \\
\hline & & \\
\hline
\end{tabular}

Table 3. Radii extracted with vertical planes passing through opposite preserved travertine pulvini (white numbers in figure 13). 3-7 was discarded since less reliable (pulvinus 7 is absent). 


\subsection{The role of contour lines}

Specific sections allow specific readings of the remains. These sections have been selected in order to carry out analysis on the supposed original drawings made by the architect (ichnographia, orthographia). Nevertheless, opus caementicium vaults are complex shapes with double curvature surfaces that result deeply altered by deterioration phaenomena and complete absence of maintenance during centuries, as well as anthropic alterations: removal of building materials and in some cases also inaccurate restorations. Hence the need of a comprehensive vision of the vaulted surface through contour lines, extracted with a variable sampling ranging from 3 to 5 centimetres. Yet a structural feature of the Roman vaulted architectures should also be remarked, which could lead to a misinterpretation of the original shape. The presence of unevenly preserved ancient thick mortar - up to 10 $\mathrm{cm}$ - laid upon masonry and concrete places a relevant issue as far as the ability to distinguish which is the supporting structure and which is the finishing.

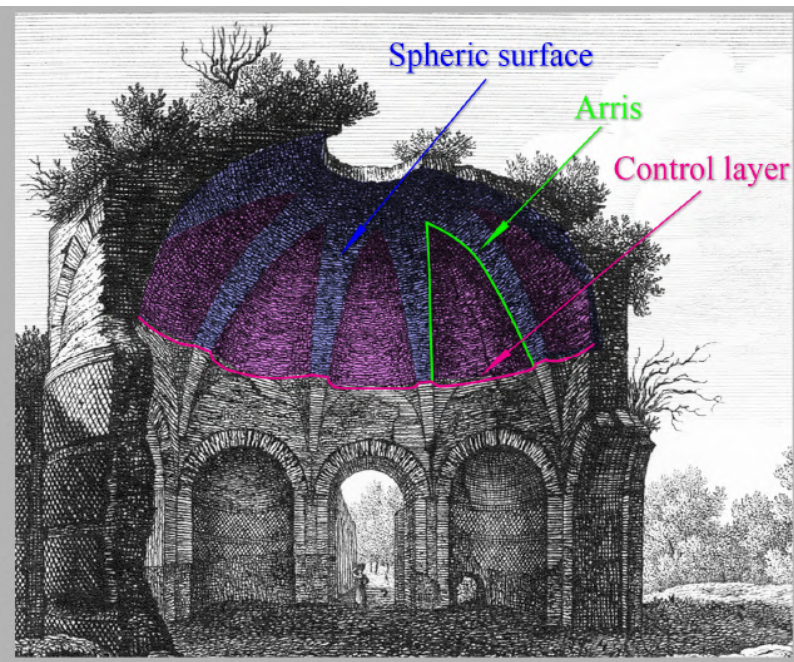

(a) (b)

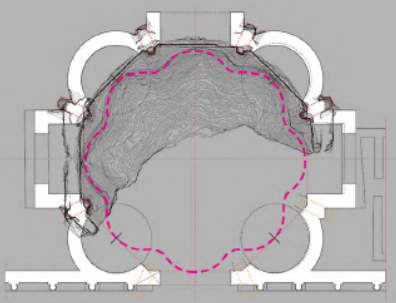

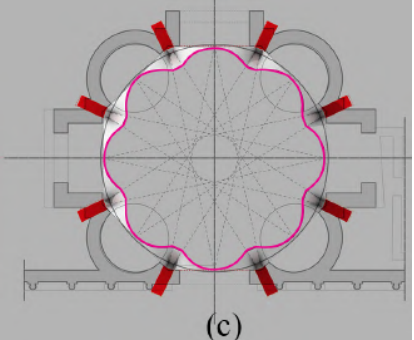

(c)
Figure 14. (a) State of conservation of the Vestibule as documented by Penna (1836). (b) Contour lines: in evidence remaining control elements of the construction. (c) Idealized shape achieved through subdivision surfaces.

Not an easy task, since automatic or semi-automatic extraction of contour lines without archaeologist and restorer interpretation may lead to incorrectly reconstruction of original formal features (Adembri et al., 2016). During the research on both the Vestibule and Small Baths a substantial support was supplied by the comparison among contour lines and historical drawings, paintings and engravings, since they supply views of the vaults before restorations, that altered both intrados and extrados (see Figure 7 and Figure 14). From here on, the use of flexible models for reconstructive hypotheses becomes increasingly important: on the one hand it is possible, through the study of measurements and geometric patterns, to obtain a coherent knowledge of the ancient project and its construction (in case of strongly degraded domes greater caution is required). From reverse modelling applications a set of reliable curves can be achieved; from historic drawings other elements emerge (but without a level of accuracy comparable to current surveys). In the case of the Vestibule it is safe to say they built a hemispherical dome, with circular arris (Figure 14a). In addition, we know from typological comparison with other buildings that Roman architects used to place control layers during the constructing phases of opus caementicium structures, but we cannot achieve - due to the state of conservation - a possible geometric construction of these elements (Figure 14b and c). In other terms: it is very difficult to build a complete and reliable procedural model, based on specific algorithms, with the exception of a set of certain geometric features.

\section{RESULTS: SUBDIVISION SURFACE INSIDE A PROCEDURAL WORKFLOW}

In order to achieve flexible models, susceptible to change during the following investigation steps and consistent with graphic codes of architectural drawing, we opted for a recent software solution based on Catmull-Clark Subdivision Surfaces (Catmull \& Clark, 1978; De Rose et al., 1998) in combination with procedural modelling. Best-fitting 2D curves from reverse modelling workflow have been exported in DXF format to The Foundry Modo (13.0) after a check phase, as well as 3D primitives of proven reliability (Figure 15).

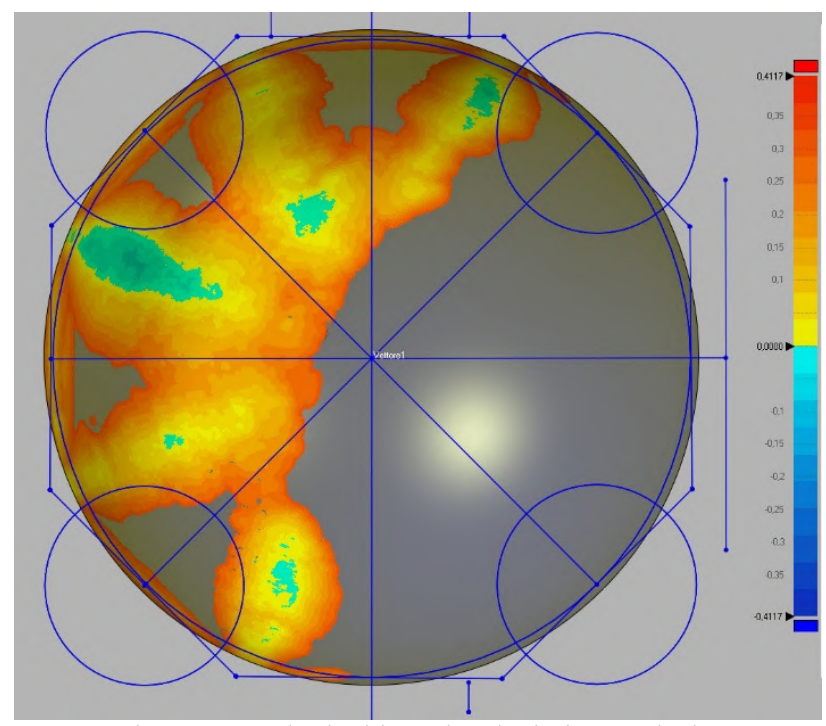

Figure 15. Spherical intrados deviation analysis.

Nevertheless, special adaptations were needed to ensure a correct fitting of each reconstructed element with the existing masonry and for this reason a lower resolution model is always imported inside the 3D geometric modelling application adopted (Figure 16). Modelling techniques - based on quad-meshes - shown their convenience, in combination with non-linear deformation tools in order to make fit idealized geometries with the remains of opus caementicium vaults: in addition, these tools can be applied procedurally and constantly revised. The choice of subdivision surfaces rather than other LOD techniques, like NURBS, or the set of tools implemented inside BIM applications is due to various justifications. The most dealing with visualization quality, as well as the possibility to set up, per each intersection curve between subdivision surfaces, an independent and always editable transition (width, profile, smooth). This last feature is relatively new, since it depends on the support of subdivision surface as sources for Boolean operations (Jiang \& Stewart, 
2009). Low density quad meshes generate LOD bicubic surfaces (of walls, of lunettes, pulvini, etc.); they present a nice curvature flow, then, they are aggregated (AND, OR, XOR) by means of a node-based interface (Schematic Workspace) that permits the definition for each subdivision surface of a "role" and a "relationship": the first means how an item contributes to the final model; it can be a primary role (add) or a trim (subtraction or intersection). The "relationship" allows the user to specify how that object role is going to affecting the final model. As other applications based on nodes, Mesh Fusion (application running under The Foundry Modo) has a canvas and components that can be connected or disconnected depending on the necessity via wires linking input and output grips, allowing to reuse source subdivision surfaces for the creation of different elements starting from a set of volumes (Figure 17). The procedure illustrated in this paper can be used to create reconstructive models suitable for the formal validation of reconstructive hypotheses. In particular, for odd vaulted spaces present at Hadrian's Villa (Ottati, 2017) it is necessary to carry out numerous revisions to the initial hypotheses, without having to reconstruct the entire digital model again, and again. This can lead to an obvious saving of time and a visually compelling result due to Catmull-Clark Subdivision Surfaces, for several years a standard in CGI industry.

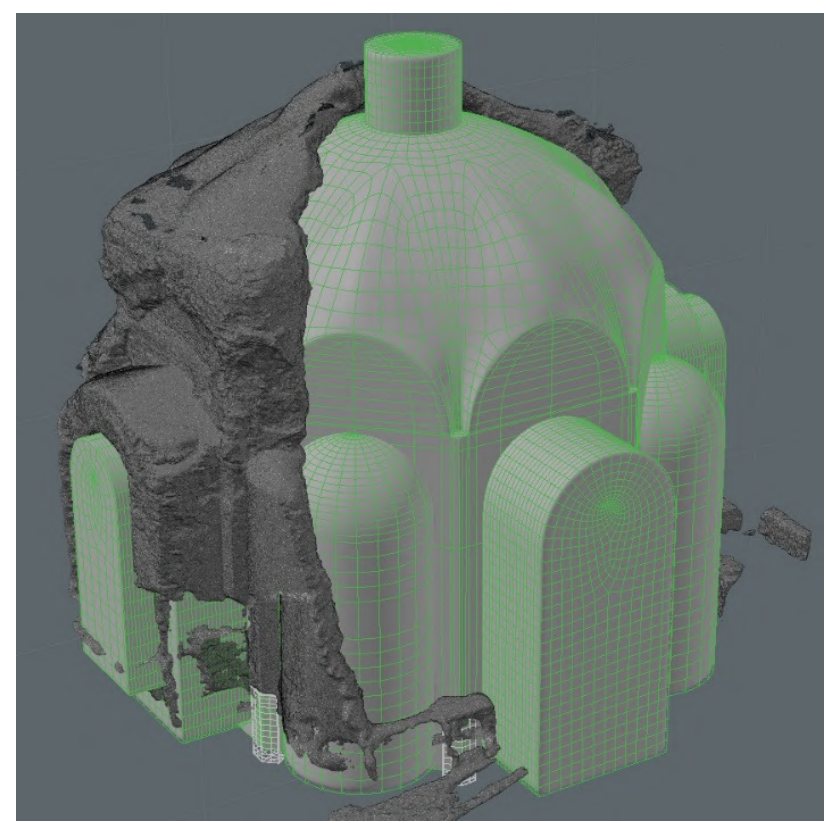

Figure 16. A "compound" of bicubic patches aimed at "carving" the external volumes of the Vestibule.

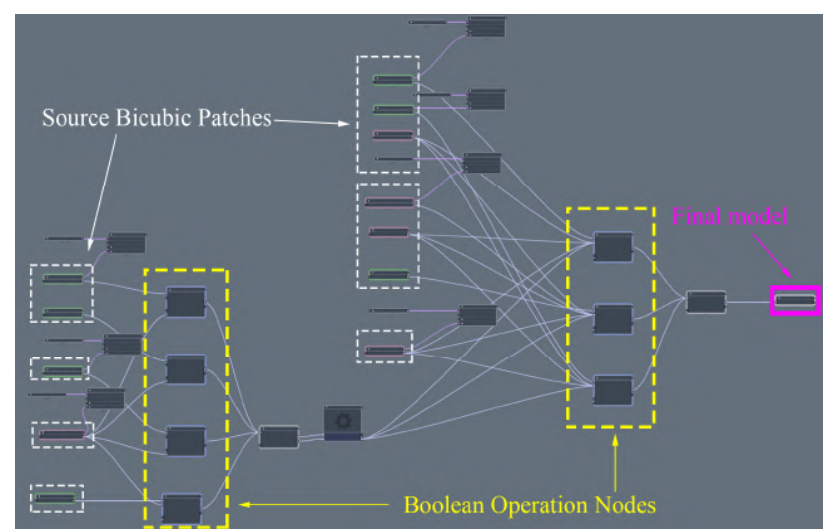

Figure 17. Schematic Workspace.

\section{REFERENCES}

Adembri, B., Alonso-Durá, A., Juan-Vidal, F., Bertacchi, G., Bertacchi, S., Cipriani, L., Fantini, F., Soriano-Estevalis, B., 2016. Modelli digitali 3D per documentare, conoscere ed analizzare l'architettura e la costruzione nel mondo antico: l'esempio della Sala Ottagonale delle Piccole Terme di Villa Adriana. Archeologia e Calcolatori, 27. All'Insegna del Giglio, Firenze, pp. 291-316.

Aliberti, L., Alonso-Rodríguez, M.Á., 2018. Digital photogrammetry for the geometrical analysis of the umbrella-shaped dome in Baia (Naples). Int. Arch. Photogramm. Remote Sens. Spatial Inf. Sci., XLII-2, pp. 23-28. https://doi.org/10.5194/isprs-archives-XLII-2-23-2018

Caliari, P., 2018. La composizione policentrica di Villa Adriana e il tecnigrafo post alessandrino. ANANKE - XIX secoli a Villa Adriana, (84), pp. 67-79.

Catmull, E., Clark, J., 1978. Recursively generated B-spline surfaces on arbitrary topological meshes. Computer Aided Design, 10(6), pp. 350355. doi:10.1016/0010-4485(78)90110-0

De Rose, T., Kass, M., Truong, T., 1998. Subdivision surfaces in character animation. SIGGRAPH' 98 Proceedings of the 25th annual conference on Computer graphics and interactive techniques. ACM, New York, pp. 85-94. doi:10.1145/280814.280826

Giuliani, C.F., 1975. Il lato nord ovest della Piazza d'Oro. Giuliani, C.F., Verduchi, P. (eds), Ricerche sull'architettura di Villa Adriana. De Luca, Roma.

Gonzalez-Aguilera, D., López-Fernández, L., Rodriguez-Gonzalvez, P., Hernández- López, D., Guerrero, D., Remondino, F., Menna, F., Nocerino, E., Ballabeni, A., Gaiani, M., 2018. GRAPHOS-open-source software for photogrammetric applications. The Photogrammetic Record, (33)161, pp. 11-29. DOI: 10.1111/phor.12231

Heiberg, J.L. (ed), 1914. Heronis Alexandrini, Opera quae supersunt omnia. Teubner, Stuttgart (rpt. 1976).

Jiang, D., Stewart, N., 2009. Robustness of Boolean Operations on Subdivision-Surface Models. Cuyt, A., Krämer, W., Luther, W., Markstein, P. (eds), Numerical Validation in Current Hardware Architectures. Springer, Berlin, pp. 161-174. doi:10.1007/978-3-64201591-5_10.

Lancaster, L.C., 2005. Concrete vaulted construction in Imperial Rome. Innovations in context. Cambridge University Press, NY.

MacDonald, W.L., Boyle, B.M., 1980. The Small Baths at Hadrian's Villa. Journal of the Society of Architectural Historians (39). University of California Press Journals, Oakland, pp. 5-27.

Opper, T. (ed), 2008. Hadrian: Empire and conflict. The British Museum Press, London, UK.

Ottati, A., 2017. Costruzione e ricostruzione dell'Accademia di Villa Adriana: dall'analisi del monumento alla restituzione. Problemi e soluzioni nell'uso della tecnologia digitale. Archeologia e Calcolatori, 28(1). All'Insegna del Giglio, Firenze, pp. 179-200. ISSN 1120-6861

Penna, A., 1836. Viaggio pittorico della Villa Adriana composto dei musaici, pitture, statue ed altri oggetti rinvenuti nelle varie escavazioni condotto da Agostino Penna con una breve descrizione di ciascun monument (Vol. 2). Tipografia di Pietro Aureli, Roma.

Rakob, F., 1967. Die Piazza d'Oro in der Villa Hadriana bei Tivoli. Dissertation Universität Karlsruhe, München.

Verdiani, G., Pucci, M., Blanco, A., 2009. The Small Baths in Hadrian's Villa. A ground test for enhancing the approach to the digital survey and reconstruction for archaeologists and architects. Proceedings of the 14th, CHNT14, Wien, Austria, pp. 259-271.

Wilson Jones, M., 2000. Principles of Roman architecture. Yale University Press, New Haven, Connecticut, USA. 